\title{
Interfacial transition zones in recycled aggregate concrete with different mixing approaches
}

\author{
Wengui Li ${ }^{\text {a,b }}$, Jianzhuang Xiao ${ }^{\mathrm{a}, *}$, Zhihui Sun ${ }^{\mathrm{c}}$, Shiho Kawashima ${ }^{\mathrm{b}}$, Surendra P. Shah ${ }^{\mathrm{b}}$ \\ ${ }^{a}$ Department of Building Engineering, Tongji University, Shanghai 200092, PR China \\ ${ }^{\mathrm{b}}$ Center for Advanced Cement-Based Materials, Northwestern University, Evanston, IL 60208, USA \\ ' Department of Civil \& Environmental Eng., University of Louisville, Louisville, KY 40292, USA
}

\section{H I G H L I G H T S}

- Nanoindentation was applied to characterize nanomechanical properties of ITZs.

- SEM was implemented to analyze the microstructures of ITZs.

- Two-stage mixing approach is proved to improve the properties of the new ITZ.

\section{A R T I C L E I N F O}

\section{Article history:}

Received 4 May 2012

Received in revised form 20 May 2012

Accepted 4 June 2012

Available online 15 July 2012

\section{Keywords:}

Recycled Aggregate Concrete (RAC)

Two-stage Mixing Approach (TSMA)

Interfacial Transition Zone (ITZ)

Nanoindentation

Microstructure

\begin{abstract}
A B S T R A C T
Interfacial Transition Zone (ITZ) is an important phase that influences the mechanical properties of Recycled Aggregate Concrete (RAC). This paper is devoted to an investigation of the effect of different mixing approaches on the properties of ITZs in RAC. Nanoindentation and Scanning Electron Microscopy (SEM) were implemented to characterize nanomechanical properties and microstructures of the old and new ITZs. The results indicate that the indentation modulus of ITZs have different distribution trends when using different mixing approaches. It reveals that the Two-Stage Mixing Approach (TSMA) can improve the nanomechanical properties of the new ITZ by reducing the volume fraction of voids and Calcium Hydroxide $(\mathrm{CH})$. The SEM observation also indicates that an obviously denser and more homogeneous microstructure was achieved in the new ITZ prepared by TSMA compared to a Normal Mixing Approach (NMA). Correlating the nanoindentation and SEM results with the compressive strength, it can be concluded that TSMA has a beneficial influence on the mechanical properties of RAC by improving the properties of the new ITZ.
\end{abstract}

(c) 2012 Elsevier Ltd. All rights reserved.

\section{Introduction}

In views of environmental protection, conservation of natural resources and shortage of lands for waste disposal, it is necessary to promote recycled aggregates for effective utilization of waste concrete. Researchers have tried to relate the quality of Recycled Aggregate Concrete (RAC) to the properties of the original waste concrete, the new mix composition, the mixing approach and the deterioration condition of the Recycled Coarse Aggregate (RCA) [1-5]. It is generally accepted that the Interfacial Transition Zones (ITZs), the quality of the old mortar, and the old mortar content of the original concrete influence the properties of the RAC. In recent years, recycling of waste concrete to produce RAC has been proven to be commercially and technically sound for both non-structural and structural applications [6-9].

\footnotetext{
* Corresponding author. Tel.: +86 2165982787; fax: +86 2165986345 .

E-mail address: jzx@tongji.edu.cn (J. Xiao).
}

Although the recycling of demolished concrete can benefit the environment, there are concerns about the structural safety and durability of the RAC structure. To improve the quality of RAC, a new mixing method: Two-Stage Mixing Approach (TSMA) has been developed by Tam et al. $[3,10]$. Using this method, the RCA was firstly mixed with cement paste, which was followed by adding natural sand to the mixture. The two-stage mixing can help to form a layer of cement slurry on the surface of RCA to fill up the initial damage such as micro-cracks and voids, leading to an improved interfacial zone at the pre-mix stage. Compared to Normal Mixing Approach (NMA), it has been demonstrated that TSMA leads to the improvement in strength and durability of RAC $[10,11]$.

Concrete is highly complex and non-homogeneous materials, and its properties depend on the properties of each individual constitutes, i.e. coarse aggregate, paste matrix and ITZs [12,13]. While researches on the strength and durability of RAC have been explored, it is still necessary to better understand the micro- and nanoscale structure and local mechanical properties of the ITZs 
in RAC. Compared to conventional concrete, RAC contains more types of ITZs $[14,15]$. The old ITZ is between the original aggregate and the old paste matrix, while the new ITZ is between the old paste matrix and the new paste matrix. One of the major reasons for the lower strength exhibited by RAC is the weak ITZs. Improving the mixing approach of RAC to enhance its ITZ properties can be helpful to improve the mechanical properties of RAC. Although some investigators have found that TSMA can significantly improve the mechanical properties and durability of RAC, to the best knowledge of the authors, very few in-deep studies related to the improvement mechanism have been done. Therefore, there is a great need to investigate the influences of mixing approaches on microstructure and nanomechanical properties of ITZs in RAC.

With the emergence of nanoindentation technology, it is now possible to directly measure the mechanical properties of the ITZs [16-19], and Scanning Electron Microscopy (SEM) is typically applied to investigate the morphological characteristic of the ITZs $[8,20]$. This study will focus on evaluating the microstructure and nanomechanical properties of ITZs in RAC prepared with different mixing approaches using nanoindention and SEM techniques. Investigating the mechanical properties of ITZs in RAC at multiple scales will provide a means for correlating micro- and nanoscale properties to macroscale application. The overall objective of this study is to improve the mechanical behavior of RAC in order to encourage and broaden the application of RAC [21,22].

\section{Materials and preparation}

The RCA in this study were from Chicago O'hare International Airport provided by Rossi Contractors Inc. (Fig. 1). The density and the absorption capacity were $2410 \mathrm{~kg} / \mathrm{m}^{3}$ and $5.73 \%$, respectively. Both RCA and natural coarse aggregate (NCA) were sieved to have the same size graduation. When casting RAC with $100 \%$ replacement of RCA, two different mixing approaches (TSMA and NMA) were used. With the TSMA approach, the RCA and cement were firstly mixed for one minute, and subsequently mixed for another one minute with half of the mixing water. Secondly, sand and the remaining water were added and mixed for two minutes. The TSMA was compared with the NMA in which the RAC, sand, cement and water were added altogether and mixed for two minutes. A mixture of normal concrete with limestone aggregate (here is called as NAC) with the same mix proportions was also designed. The mixture proportions of RAC and NAC are listed in Table 1. Throughout the whole process of this study, all the specimens were cured under $25^{\circ} \mathrm{C}$ and $55 \%$ humidity. The compressive strength was obtained by testing with $100 \mathrm{~mm}$ by $200 \mathrm{~mm}$ cylindrical specimens at 7, 28 and 90 days. The reported compressive strength value is the average of three measurements. The compressive strength of RAC with NMA was lower than that of NAC, especially at the later ages (see Fig. 2). However, the compressive strength of RAC with TSMA was comparable to that of NMA. These results again indicate that TSMA is an effective method for enhancing the mechanical properties of RAC. The strength discrepancy between the two kinds of RACs respectively prepared with NMA and TSMA can be due to the influences of mixing approaches on microstructure and nanomechanical properties of ITZ, which will be investigated in the following details.

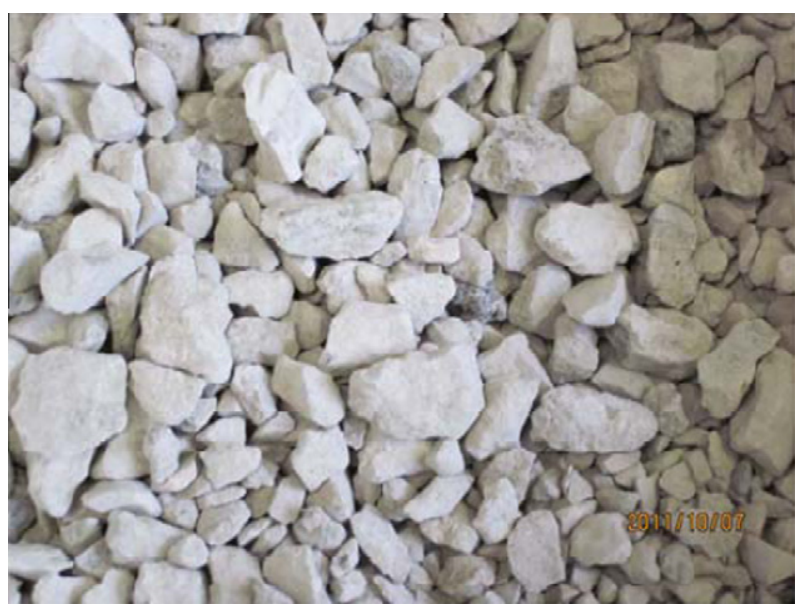

Fig. 1. Recycled coarse aggregate from Rossi Contractors Inc. in Chicago.
Table 1

Mixture proportion

\begin{tabular}{|c|c|c|c|c|c|c|c|}
\hline & \multirow[t]{3}{*}{$\mathrm{W} / \mathrm{C}$} & \multicolumn{5}{|l|}{$\mathrm{kg} / \mathrm{m}^{3}$} & \multirow[t]{3}{*}{ Mixing approach } \\
\hline & & \multirow[t]{2}{*}{ Water } & \multirow[t]{2}{*}{ Cement } & \multirow[t]{2}{*}{ Sand } & \multicolumn{2}{|c|}{ Coarse aggregate } & \\
\hline & & & & & RCA & NCA & \\
\hline RAC & 0.45 & 200 & 444 & 702 & 1054 & 0 & TSMA \\
\hline RAC & 0.45 & 200 & 444 & 702 & 1054 & 0 & NMA \\
\hline NAC & 0.45 & 200 & 444 & 702 & 0 & 1054 & NMA \\
\hline
\end{tabular}

Note: Both RCA and normal aggregate (NA) are in saturated surface dry condition.

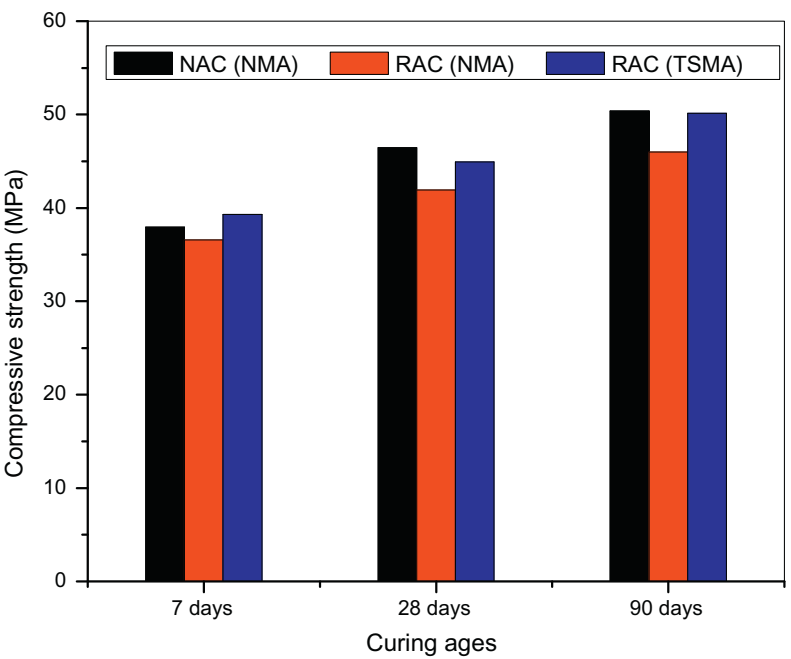

Fig. 2. Compressive strength development of different concrete.

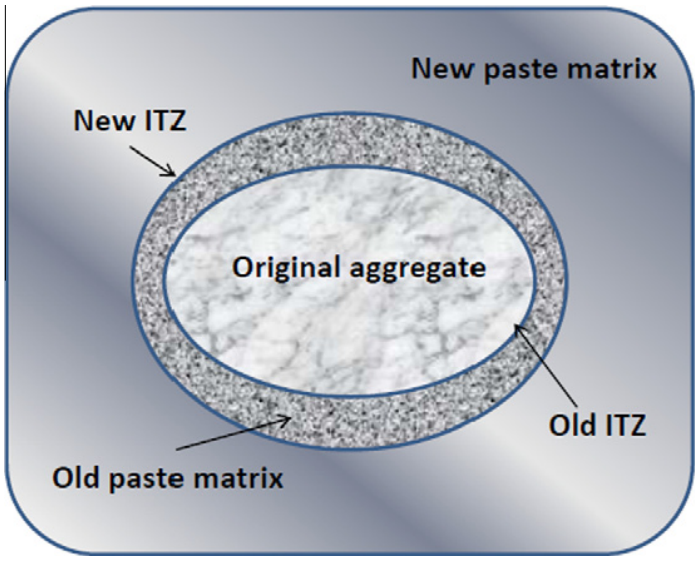

Fig. 3. Schematic diagram of old and new ITZ in RAC.

For nanoindentation, RAC blocks were cored out from the cylinders after the compressive testing at 90 days. The schematic of the old ITZ and new ITZ in RAC is shown in Fig. 3. The cored RAC block was sliced into $5 \mathrm{~mm}$ thick samples. The sample was then embedded in epoxy resin and ground with Beuhler-Met paper discs. There were two stages for the polishing procedure [23]. Firstly, the sample surface was polished on a Buehler TexMet pad using diamond suspensions with gradations of 9,6 and $3 \mu \mathrm{m}$. In this stage, the elevated soft phases of the sample surface were removed. Secondly, diamond lapping films with gradations of 3,1 and $0.5 \mu \mathrm{m}$ were used for polishing to remove the elevated hard phases. The polishing was considered completed when the measured root-mean-square roughness of the sample surface was lower than one third of the average indentation depth, which could avoid the effect of surface roughness on the nanoindentation results [24].

SEM examinations were carried out on the fracture surfaces of the RAC after the compression test. Before SEM test, the hydration was arrested by placing the sample in acetone for $24 \mathrm{~h}$. The sample surface was sputter-coated with a layer of $10 \mathrm{~nm}$ 
thick copper. The samples were observed in a SEM (Hitachi S-4800 FE-SEM providing high magnification) equipped with Energy-Dispersive X-ray (EDX) analytical facility, which can provide chemical information.

\section{Nanoindentation}

\subsection{Nanoindentation on ITZs}

\subsubsection{Test preparation}

Nanoindentation test was performed on RAC samples of 90 days old using a Hysitron Triboindenter with a Berkovitch tip (radius of $0.6 \mu \mathrm{m}$, angle of $142.3^{\circ}$ ). The indenter shape was carefully calibrated by indenting a silica sample with a well known Young's modulus of $69.5 \mathrm{GPa}$. The nanoindentation experiments were performed by single cycles loading with a maximum load of $1200 \mu \mathrm{N}$. To ensure a sufficient population of indents to conduct a statistical analysis, grids of $21 \times 11$ and $31 \times 11$ indents ( $5 \mu \mathrm{m}$ in the $\mathrm{X}$ direction and $10 \mu \mathrm{m}$ in the $\mathrm{Y}$ direction) were performed across the old ITZs and new ITZs, respectively (Fig. 4). Due to the heterogeneity of the materials, four indent areas from each sample were selected randomly and tested. The loading-unloading curves for each indent were recorded, and the modulus and hardness were obtained from the elastic unloading curves using the Oliver and Pharr approach $[18,23,25]$.

In cement-based material, each phase has different mechanical properties and thereby returns a different load-depth response, as shown in Fig. 5. In addition to the mechanical properties of different phases, the grid-indentation technique can obtain the volume fraction of each phase as well $[16,26]$. Generally, ITZ can be considered to consist of four phases including porosity, calcium hydroxide, other hydration product (primarily calcium hydrate and ettringite, etc.) and unhydrated cement grain. The ettringite is usually found in small quantities in ITZ region. Moreover, it is intimately intermingled with low density Calcium Silicate Hydrate $(\mathrm{C}-\mathrm{S}-\mathrm{H})$ and calcium hydroxide $(\mathrm{CH})$ in the groundmass $[27,28]$. Because the modulus of ettringite is similar to that of $\mathrm{C}-\mathrm{S}-\mathrm{H}$, ettringite was not considered as a discrete phase in this study, instead it is assumed to exist in the Other Hydration Product (OHP) phase $[29,30]$. The grid spacing was larger than the characteristic size of the indentation marks, so as to avoid the interaction between indents, and larger than the characteristic size of the different phases, therefore the probability of encountering each phase is similar to the surface fraction occupied by the phase on the indentation surface.

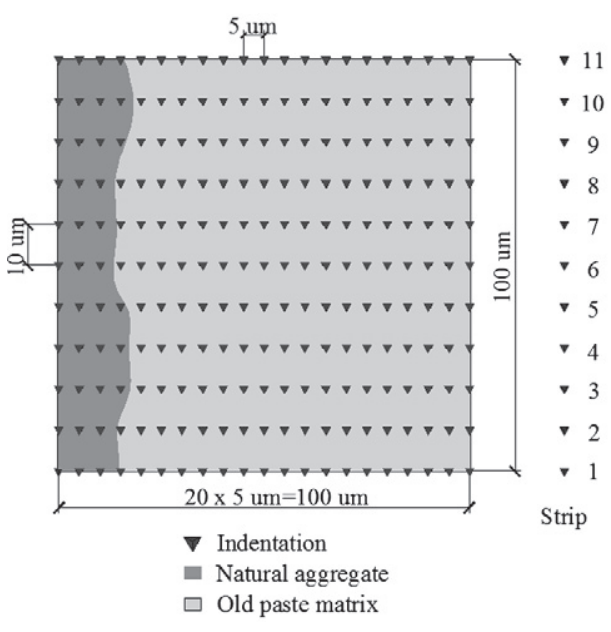

(a) Old ITZ $(\mathbf{2 1} \times \mathbf{1 1}=\mathbf{2 3 1}$ indents $)$

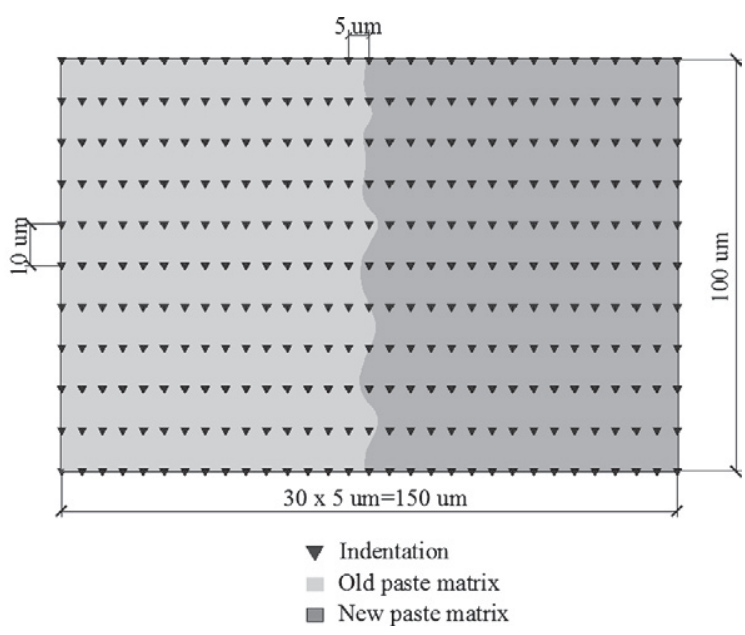

(b) New ITZ (31 $\times \mathbf{1 1 = 3 4 1}$ indents $)$

Fig. 4. Indent area schematic diagram of old ITZ and new ITZ in RAC.

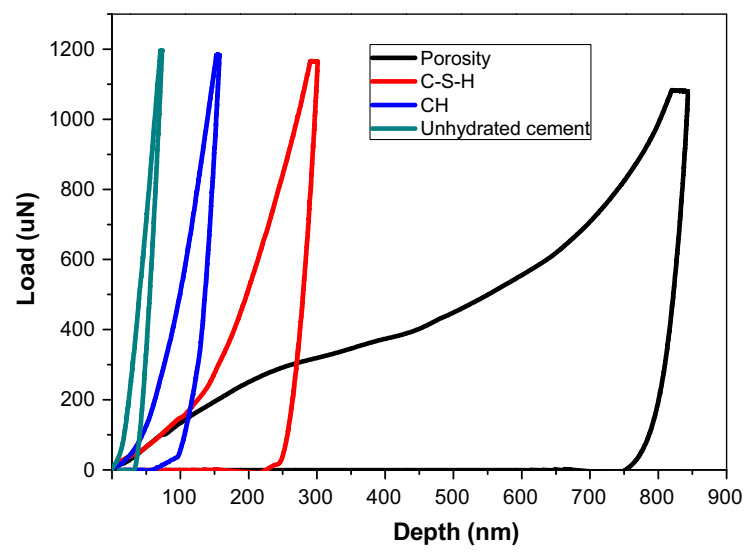

(a) Load-depth diagrams of different phases

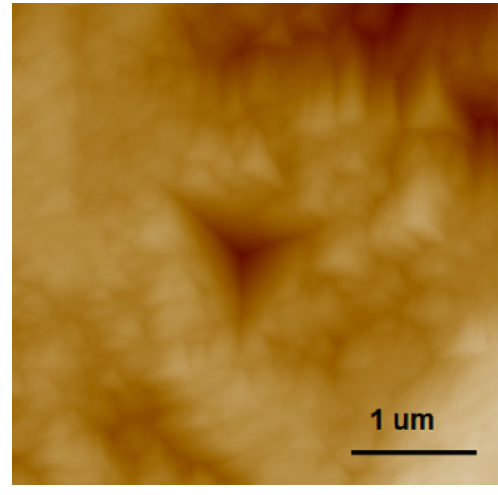

(b) Indent mark on C-S-H phase

Fig. 5. Typical indentation in ITZ. 


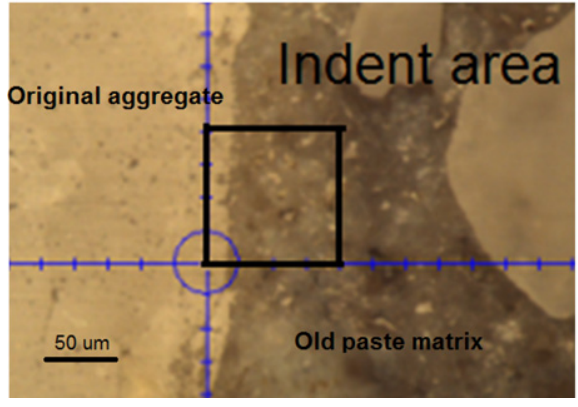

(a) Indent area for old ITZ in RAC

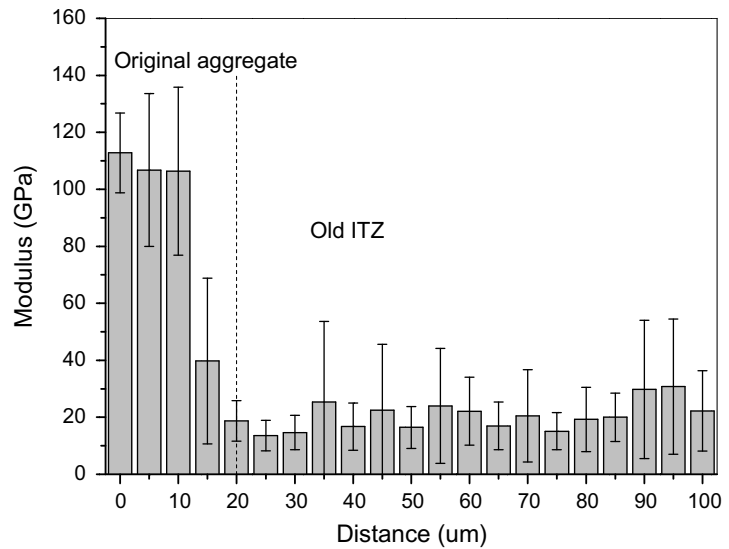

(c) Modulus distribution across old ITZ

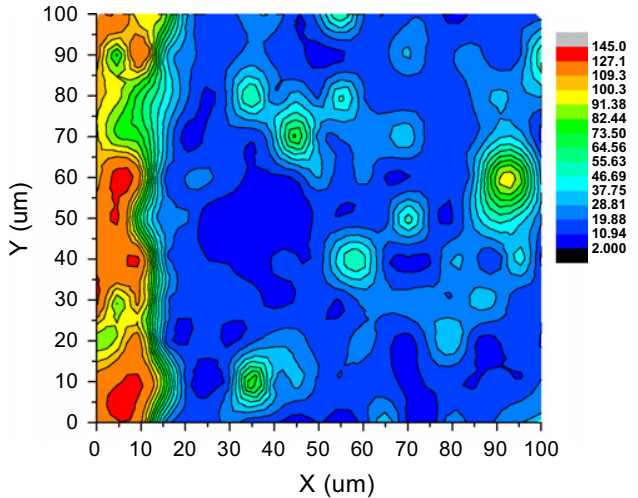

(b) Contour map of indentation modulus [GPa]

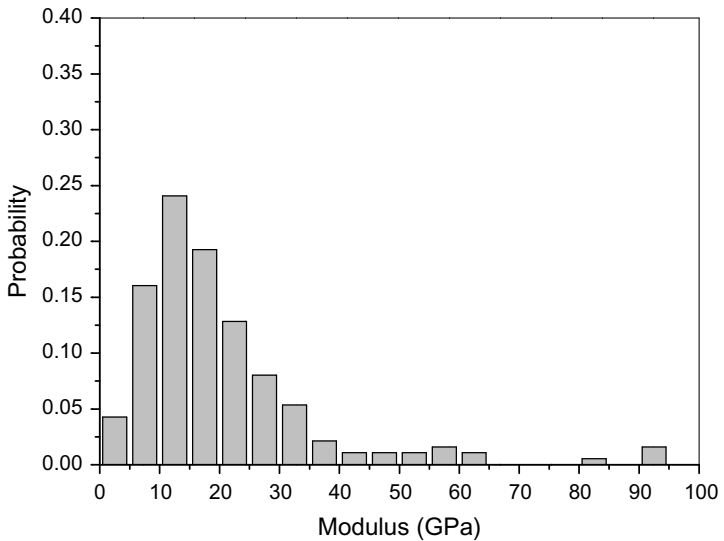

(d) Statistical analysis of modulus [bin-size $=5$ ]

Fig. 6. Nanoindentation in old ITZ (one of four indent areas).

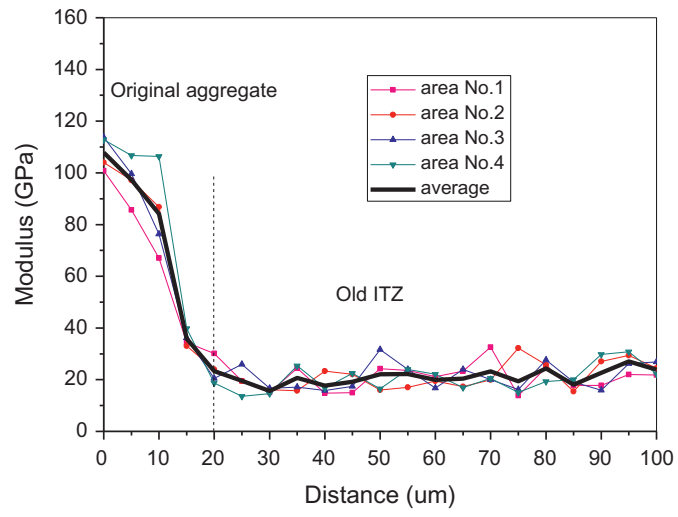

(a) General modulus distribution

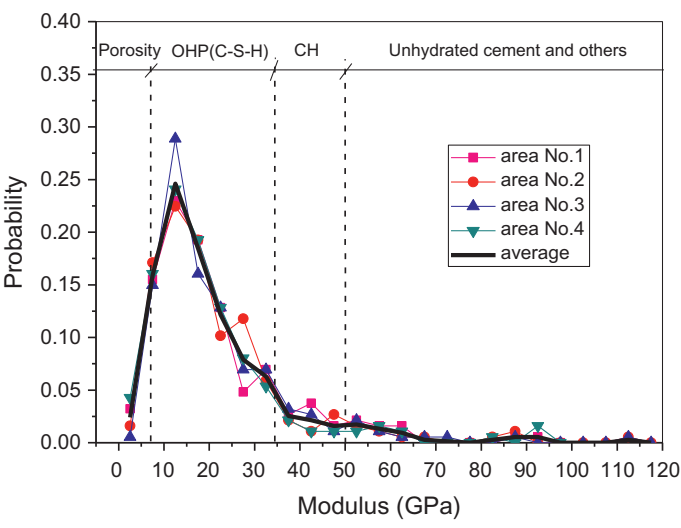

(b) General modulus probability

Fig. 7. Indentation modulus distribution in old ITZ.

Such large matrices of indents allow for statistical analysis to be performed. For each indents area, a contour map, modulus distribution and frequency histogram were obtained. In situ 2D mapping of mechanical properties allowed for examining the properties of the different phases independently of each other. The indentation modulus distribution consisted of statistical average and deviation values along the length ( $x$ direction) of the indent area. The binsize was $5 \mathrm{GPa}$ in the frequency histograms of modulus, which were used to determine the volume fraction of different phases.

\subsubsection{Old ITZ}

Considering the old ITZ being between old mortar and natural aggregate, it is assumed that the old ITZ would not influenced by the mixing approach. The following investigated old ITZ was from the TSMA. In order to obtain representative distributions of the mechanical properties in old ITZ, 4 grid areas of 231 indentations were performed, and then statistical analysis was carried out, correspondingly. Mechanical response distribution represented as frequency plots are employed to analyze indentation data on old ITZ. 


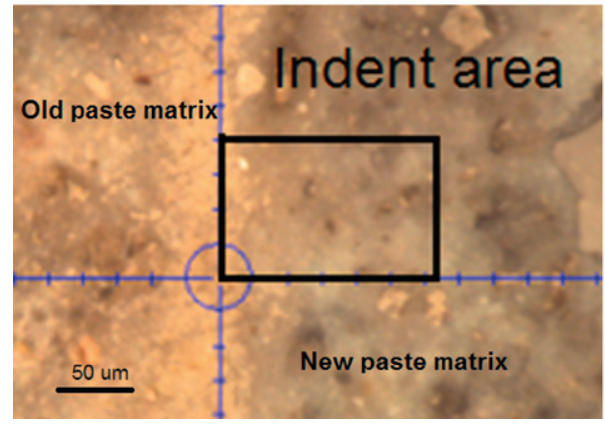

(a) Indent area for new ITZ in RAC

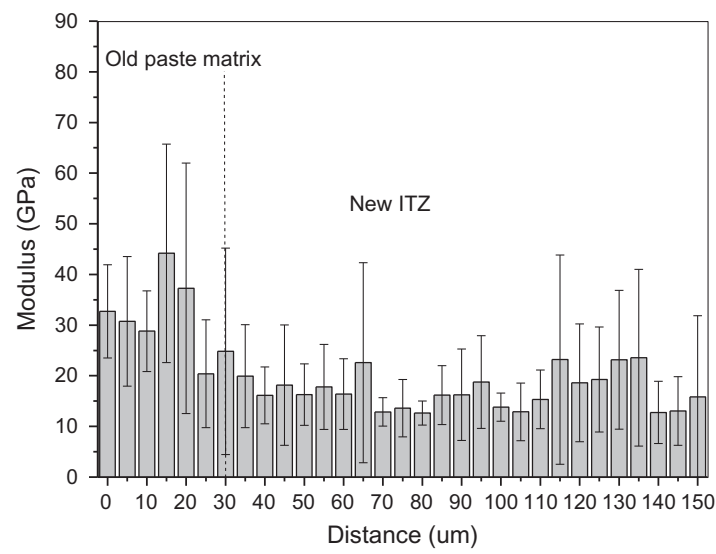

(c) Modulus distribution across new ITZ

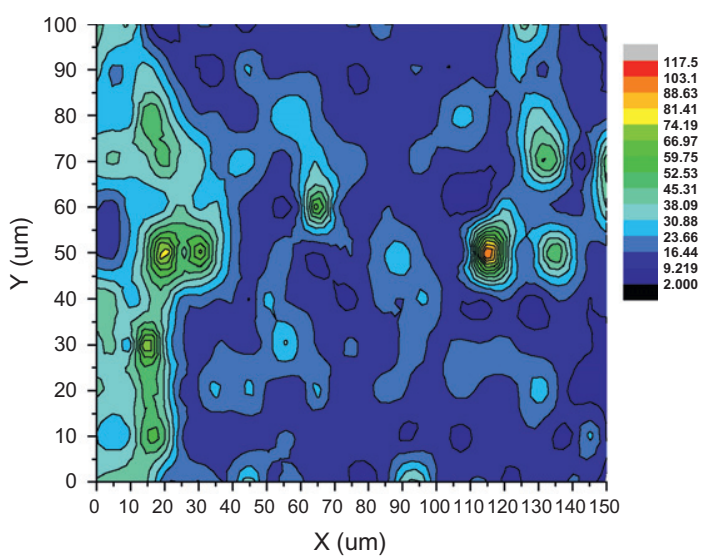

(b) Contour map of indentation modulus [GPa]

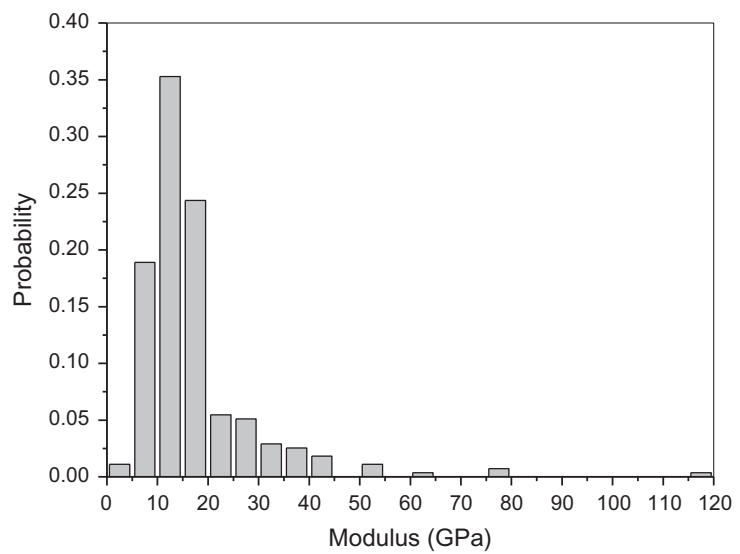

(d) Statistical analysis of modulus [bin size $=5$ ]

Fig. 8. Nanoindentation in new ITZ with TSMA (one of four indent areas).

All the four grid areas in old ITZ give similar nanoindentation results. Fig. 6 shows the nanoindentation results for one of the four grid areas in old ITZ shown as Fig. 6a. The indentation modulus contour and histogram seem to exhibit variations which are related to the modulus values of different phases.

Fig. $6 \mathrm{~b}$ represents the in situ 2D mapping of mechanical properties in old ITZ using nanoindentation for examining the properties of different phases independently of each other. In order to identify the indentation modulus distribution, statistical average and deviation value were applied to histograms of modulus across the old ITZ (Fig. 6c). To identify different phases, the bin-size for deconvolution of the indentation modulus is $5 \mathrm{GPa}$, and the frequency histogram was plotted to show the volume fraction distribution in the old ITZ (Fig. 6d). It can be found that the dominant phase in the old ITZ is OHP, especially the C-S-H gel.

The overall results from 4 grid areas are averaged and plotted in Fig. 7a. Results revealed that the indentation modulus increases with increasing distance from the original aggregate surface. The indentation modulus range of the different phases in the ITZ can be assumed to be as following: porosity ( $\leqslant 7 \mathrm{GPa}$ ), other hydration product (7-34 GPa), $\mathrm{CH}(34-50 \mathrm{GPa})$ and unhydrated cement $(\geqslant 50 \mathrm{GPa})[16,17,30,31]$. The results supplied by the normalized probability represent the mechanical properties of each phase as the surface volume fractions. Fig. $7 \mathrm{~b}$ shows the mean probability density of each phase in the old ITZ starting from the original aggregate surface with $5 \mu \mathrm{m}$ spacing. It is apparent that the OHP (C-S-H gel) is the main compound in the old ITZ, exhibiting a volume fraction of about $69 \%$.

\subsubsection{New ITZ with TMSA}

Nanoindentation was performed over 4 grid areas (341 indents each) on the new ITZ with TSMA (Fig. 8a). Fig. 8b shows the in situ $2 \mathrm{D}$ mapping of one indentation grid across the new ITZ. It shows that the indentation modulus of the old paste matrix region adjacent to the new ITZ is obviously higher compared to the other regions. The distribution of statistic indentation modulus across the new ITZ is shown in Fig. 8c. The modulus gradient of the new ITZ is variable, which may be attributed to the greater porosity and heterogeneity of the new ITZ compared to the bulk cement paste. From the statistical indentation modulus of new ITZ with TSMA, it is apparent that the main compound in the new ITZ was also OHP (primarily C-S-H gel), and the content is close to that in old ITZ (Fig. 8d).

The results from all the four grid areas across the new ITZ with TSMA are plotted in Fig. 9a. The four indent areas yielded similar indentation modulus distributions with no obvious trend indicating that the indentation modulus increase or decrease with increasing distance from the old paste matrix surface. The statistic probability density of each phase in the new ITZ was measured starting from the old paste matrix surface with $5 \mu \mathrm{m}$ spacing (Fig. 9b). The $\mathrm{C}-\mathrm{S}-\mathrm{H}$ gel is one of complicated materials in cement-based materials, which can be divided into low density $\mathrm{C}-\mathrm{S}-\mathrm{H}$ and high density $\mathrm{C}-\mathrm{S}-\mathrm{H}[17,32]$. The low density $\mathrm{C}-\mathrm{S}-\mathrm{H}$ has a dominant volume fraction of the other hydration product, which suggests that the low density $\mathrm{C}-\mathrm{S}-\mathrm{H}$ volume content in the new ITZ with TSMA is higher compared to the old ITZ. In addition, the OHP $(\mathrm{C}-\mathrm{S}-\mathrm{H})$ exhibits a volume fraction of about $68 \%$ in new ITZ with TSMA. 


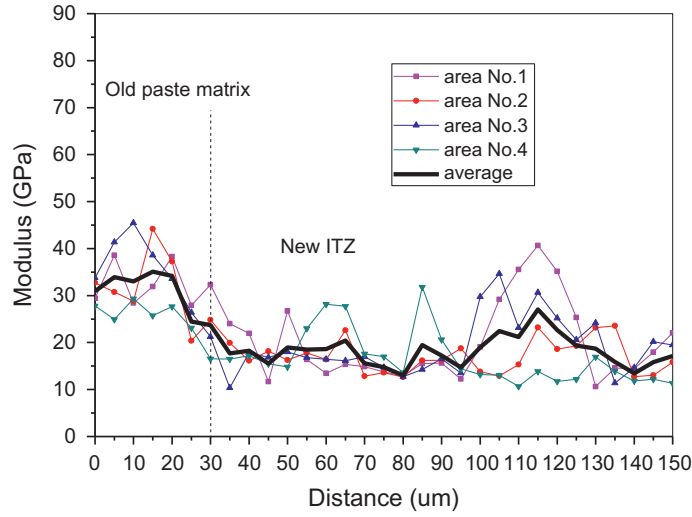

(a) General modulus distribution

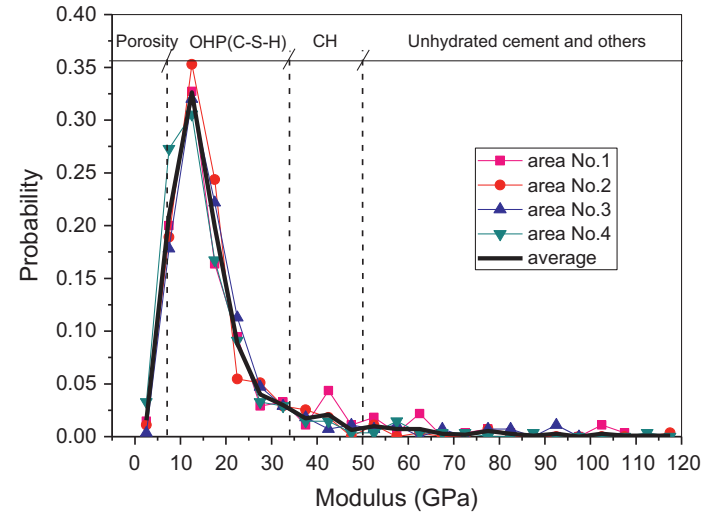

(b) General modulus probability

Fig. 9. Nanomechanical properties characteristics of new ITZ with TSMA.

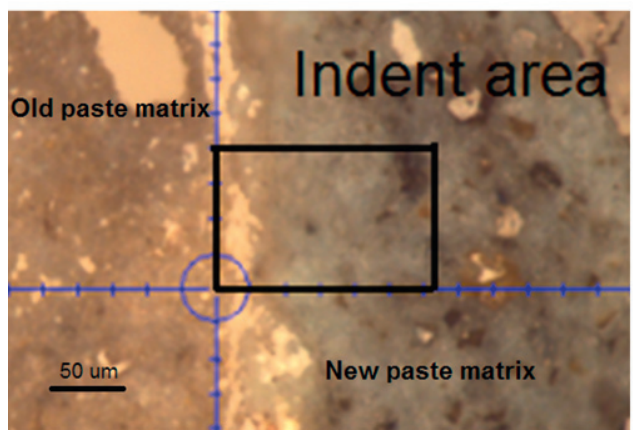

(a) Indent area for new ITZ in RAC

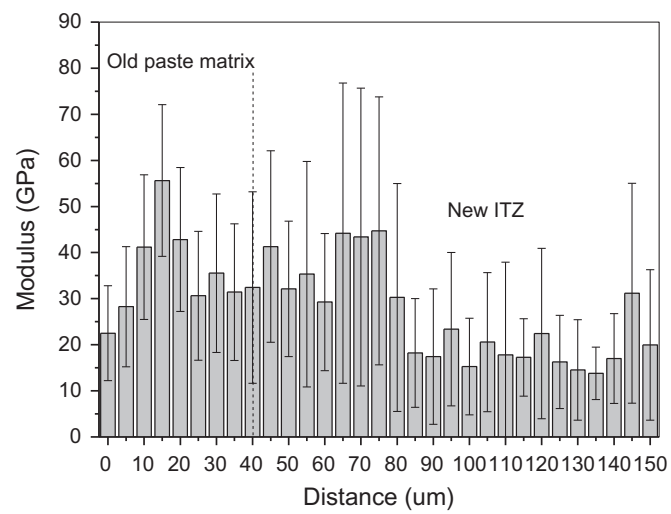

(c) Modulus distribution across new ITZ

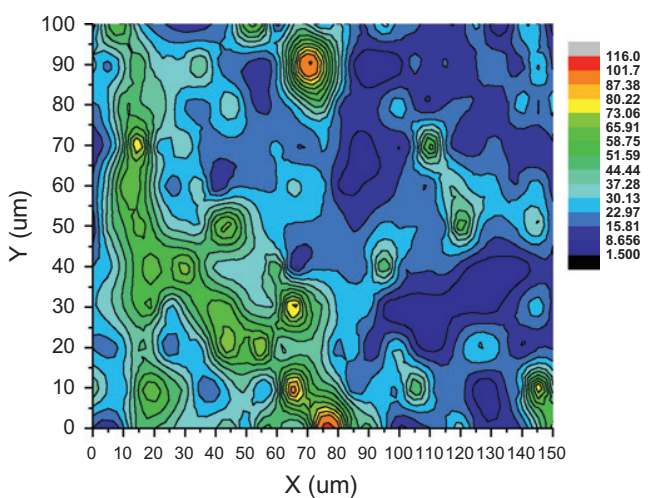

(b) Contour map of indentation modulus [GPa]

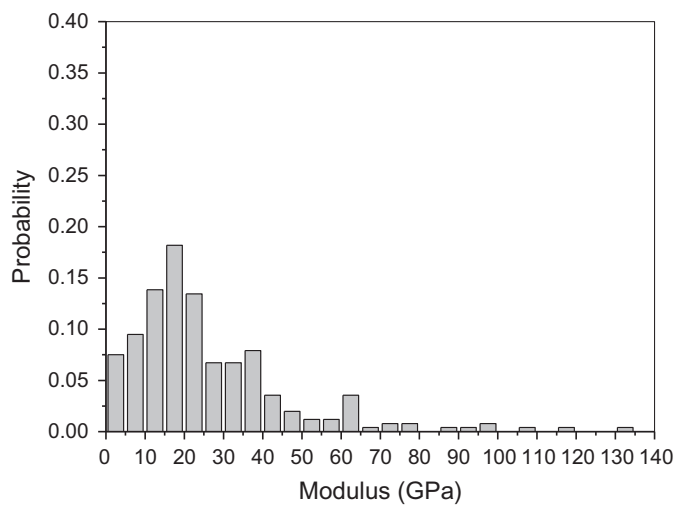

(d) Statistical analysis of modulus [bin-size $=5]$

Fig. 10. Nanoindentation in new ITZ with NMA (one of four indent areas).

\subsubsection{New ITZ with NMA}

Nanoindentation was performed over 4 grid areas (341 indents each) in the new ITZ with NMA as shown in Fig. 10a. From Fig. 10b, it appears that the old paste matrix region adjacent to the new ITZ has a higher indentation modulus. The indentation modulus distribution of the new ITZ with NMA is plotted versus the distance from the old paste matrix to new paste matrix (Fig. 10c). Compared to the old ITZ and new ITZ with TSMA, the variation in modulus along the new ITZ with NMA is significantly greater. Similar to the old ITZ and new ITZ with TSMA, OHP phase is also the main component in new ITZ with NMA, but it appears to contain relatively greater amount of porosity, $\mathrm{CH}$ and unhydrated cement grain as displayed in Fig. 10d.

The average distribution of the indentation modulus in the new ITZ with NMA is shown in Fig. 11a. Results reveal that the modulus decreases with the increasing distance from the old paste matrix surface. This may be due to the presence of large deposits of $\mathrm{CH}$ in the vicinity of the old paste matrix surface. The discussion here is qualitative in nature and will be followed with quantitative microstructural analysis. Fig. 11b shows the statistic probability density of each phase in the new ITZ with NMA. The high volume fraction of porosity, $\mathrm{CH}$ and unhydrated cement can help to explain 


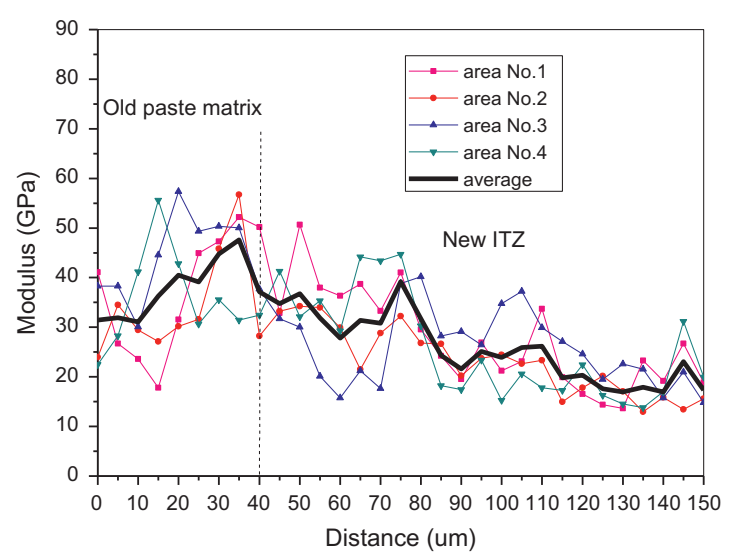

(a) General modulus distribution of old ITZ

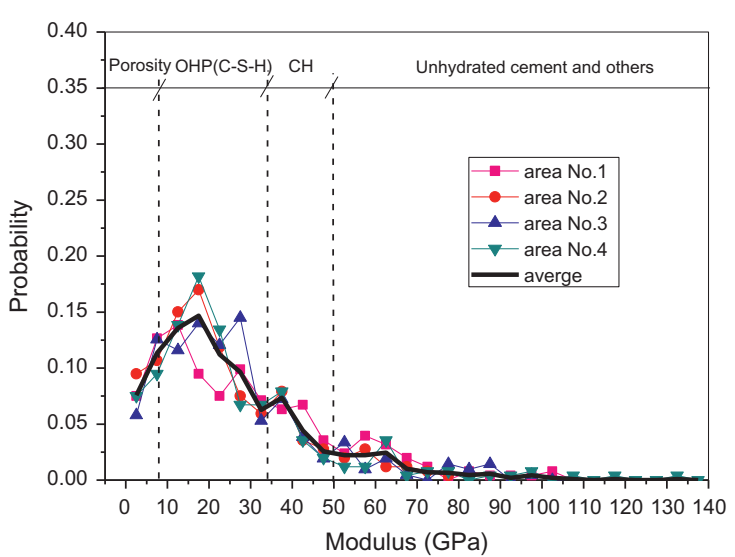

(b) General modulus probability in old ITZ

Fig. 11. Nanomechanical properties characteristics of new ITZ with NMA.

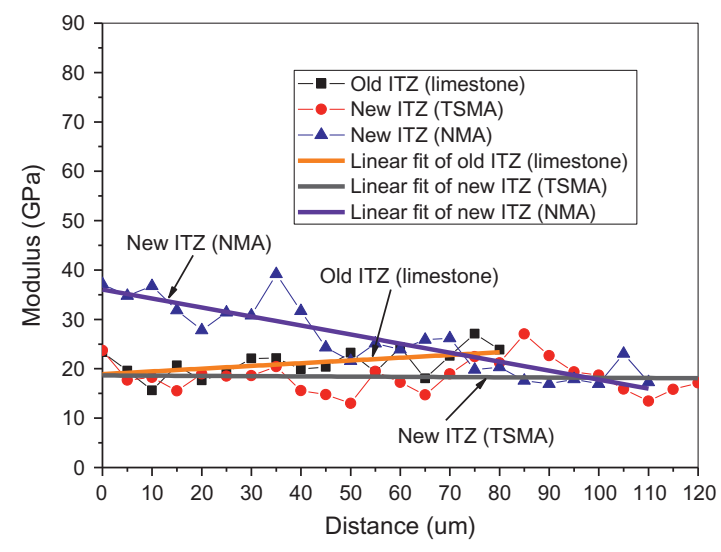

(a) Average modulus distribution of ITZs

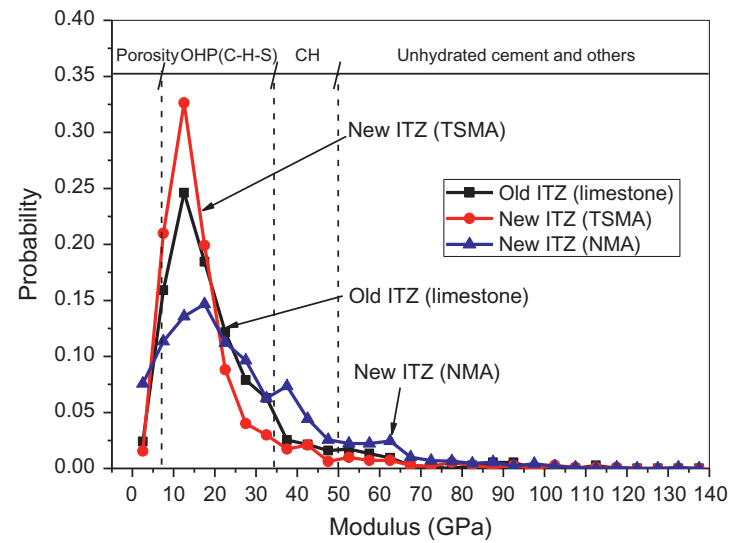

(b) Average modulus statistic analysis of ITZs

Fig. 12. Nanomechanical properties characteristics of old ITZ and new ITZ in RAC.

the higher variation in the modulus distribution in the new ITZ with NMA. In addition, the OHP (C-S-H) phase exhibits a volume fraction of about $55 \%$ in the new ITZ with NMA, which is much lower than those in the old ITZ and new ITZ with TSMA.

\subsubsection{Discussions}

Based on the nanoindentation researches on cement paste matrix $[17,18,33,34]$, the properties of the different phases (porosity, $\mathrm{CH}, \mathrm{OHP}$ and unhydrated cement) in cement-based materials have been found to be independent of the mix proportion and can be considered as intrinsic materials. The results presented here are the indentation modulus of the old ITZ and new ITZ measured at four indent areas with a distance from the original aggregate and old paste matrix surface, respectively. The distributions of modulus values measured in three types of ITZs using statistic linear fitting are plotted against the distance, as shown in Fig. 12a. It can be seen that the results display noticeable differences among the old ITZ, new ITZ with TSMA and new ITZ with NMA. For the old ITZ, the indentation modulus increases with the increasing distance from original aggregate surface. There is no obvious trend indicating that the indentation modulus of the new ITZ with TSMA increases or decreases with the increasing distance from the old paste matrix surface. In case of the new ITZ with NMA, it shows that the modulus distribution appears to decrease significantly from the old paste matrix surface.
The nanoindentation results also provide an indirect method of estimating the volume fraction of porosity, OHP (primarily $\mathrm{C}-\mathrm{S}-\mathrm{H}$ ), $\mathrm{CH}$ crystals and unhydrated cement in ITZs (Fig. 12b). The probability plot of cement paste falls between 7 and 34 GPa corresponds to the OHP phases. The probability below $7 \mathrm{GPa}$ and above $50 \mathrm{GPa}$ correspond to the voids phase and unhydrated cement phase, respectively. It is observed that the volume fractions of porosity and $\mathrm{CH}$ phases in the new ITZ with NMA are relatively higher than those of the old ITZ and new ITZ with TSMA. However, the probability of modulus which corresponds to the porosity and $\mathrm{CH}$ phases were significantly reduced for the new ITZ with TSMA. It indicates that the TSMA can effectively reduce the size and effect of water layers formed around the RCA. Therefore, the amount of porosity in the new ITZ is reduced while the enhanced hydration provides a source for production of $\mathrm{C}-\mathrm{S}-\mathrm{H}$. This suggests that the TSMA has a direct correlation to improve the properties of the new ITZ, and help explain the improvement in compressive strength.

\subsection{Nanoindention on paste matrices}

The old paste matrix and new paste matrix were also investigated by nanoindentation as well. The main components of the paste matrix in RAC can also be assumed to contain porosity, $\mathrm{CH}$, OHP and unhydrated cement. Nanoindentation was performed in serials of grids of 121 indents covering a representative area of 


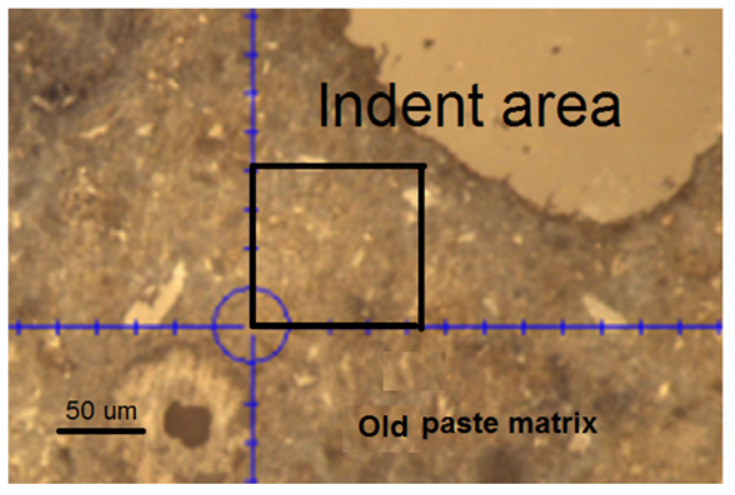

(a) Indent area for old paste matrix

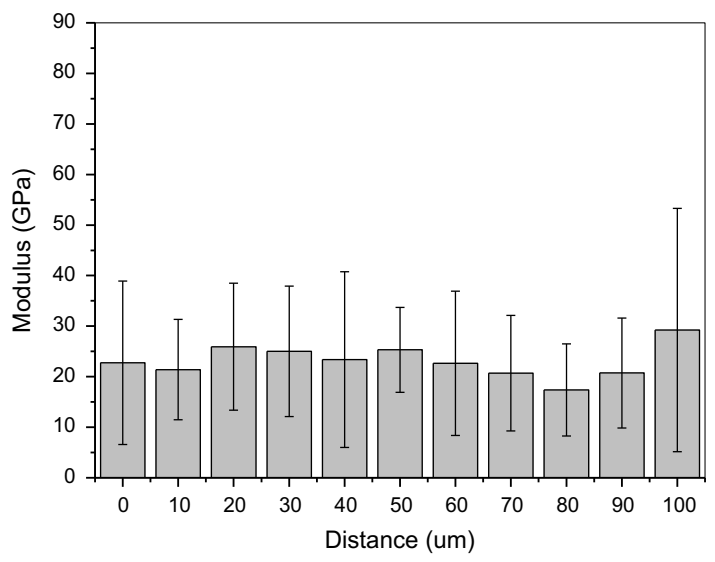

(c) Modulus distribution in old paste matrix

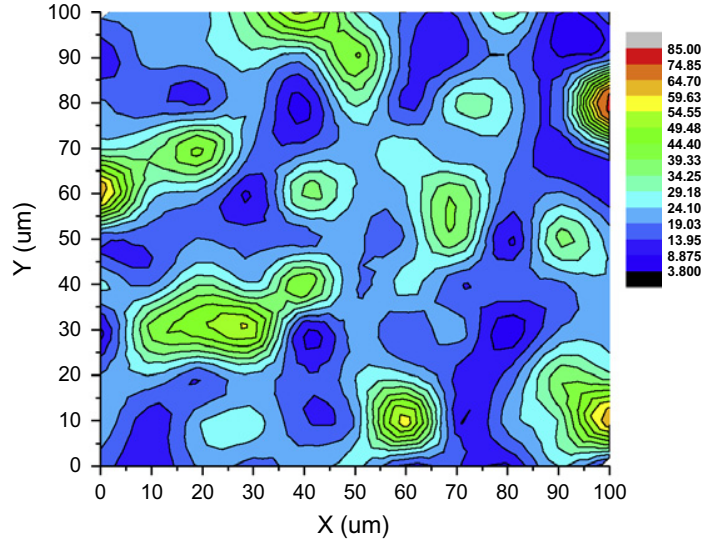

(b) Contour map of indentation modulus [GPa]

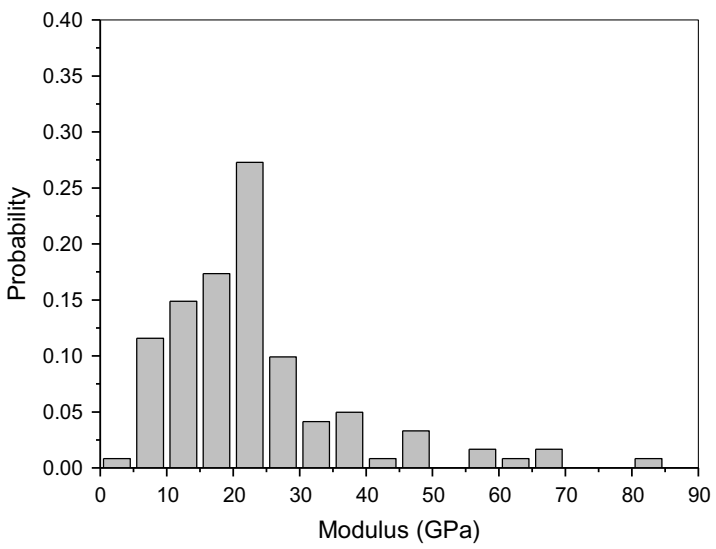

(d) Statistical analysis of modulus [bin-size=5]

Fig. 13. Nanoindentation in old paste matrix.

$100 \times 100 \mu \mathrm{m}$ on the surface of the paste matrix with the indent spacing of $10 \mu \mathrm{m}$. The indent areas of the paste matrices were examined using an optical microscopy.

Fig. 13a and b shows an optical image and contour map of the indent area in the old paste matrix, respectively. All the different grid areas on the old paste matrix showed similar results. They indicate that there is a less concentration of unhydrated cement and $\mathrm{CH}$ deposition than those seen in the ITZs. Results of mean values and standard deviation for the indentation modulus in the old paste matrix are shown in Fig. 13c. Compared to ITZs, no significant variations in the modulus distribution were found. This phenomenon is most likely due to a decrease in the amount of porosity, $\mathrm{CH}$ and unhydrated cement. Statistical probability of individual phases in the old paste matrix is shown in Fig. 13d, in which the $\mathrm{C}-\mathrm{S}-\mathrm{H}$ phase is the dominant, and the presence of unhydrated cement is limited. It is also apparent that the variation in modulus was smaller in the old paste matrix than in the ITZs.

For the new paste matrix, the optical image of the area of indents is shown in (Fig. 14a). The 2D in situ indentation modulus map also reveals more variation in properties across the new paste matrix (Fig. 14b). The areas of relatively higher modulus in the sample area correspond to the areas of unhydrated cement, while the lower modulus areas correspond to those with the porosity phases. The variation in indentation modulus of the new paste matrix is similar to that of the old paste matrix, but significantly lower than that in the ITZ regions (Fig. 14c). Statistical analysis was applied to obtain the modulus probability of each phase in the new paste matrix (Fig. 14d). Comparing the probability density of the new paste matrix and old paste matrix, it is apparent that the volume fractions of the two types of $\mathrm{C}-\mathrm{S}-\mathrm{H}$ are different, which might have contributed to the differences in nanomechanical properties.

Compared to the ITZs, the distributions of indentation modulus of the paste matrices are much less variable (Fig. 15a). It reveals that within the old and new paste matrix, the modulus appears to remain constant. Moreover, the variation in properties of paste matrix is similar with the new ITZ with TSMA, but appreciably lower than that of the new ITZ with NMA.

It is observed that the peak of the modulus probability plot for the new paste matrix falls between 15 and $20 \mathrm{GPa}$, corresponding to low density $\mathrm{C}-\mathrm{S}-\mathrm{H}$, while the peak of modulus probability plot for the old paste matrix is between 20 and $25 \mathrm{GPa}$ (Fig. 15b). Comparing the new paste matrix and old paste matrix, it is apparent that the amount of low density $\mathrm{C}-\mathrm{S}-\mathrm{H}$ and high density $\mathrm{C}-\mathrm{S}-\mathrm{H}$ phases were changed with the curing age.

\section{Microstructural characterization of ITZs}

SEM imaging was carried out on the fracture surfaces of RAC sample after compression tests as show in Fig. 16. It also can be seen that there are some of well-crystallized $\mathrm{CH}$ and a moderate amount of whisker-like ettringite crystal in the hydrates (Fig. 16a) [35,36]. The microstructure of the new ITZ with TSMA is somewhat different from that in the old ITZ (Fig. 16b). It shows that there are less whisker-like ettringite crystals. For the new ITZ with NMA, there are significantly higher porosity and amount of $\mathrm{CH}$ crystals, which is substantially different from those observed 


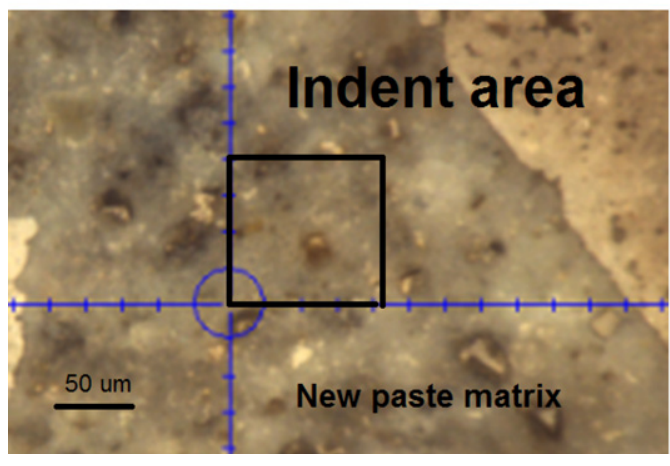

(a) Indent area for new paste matrix

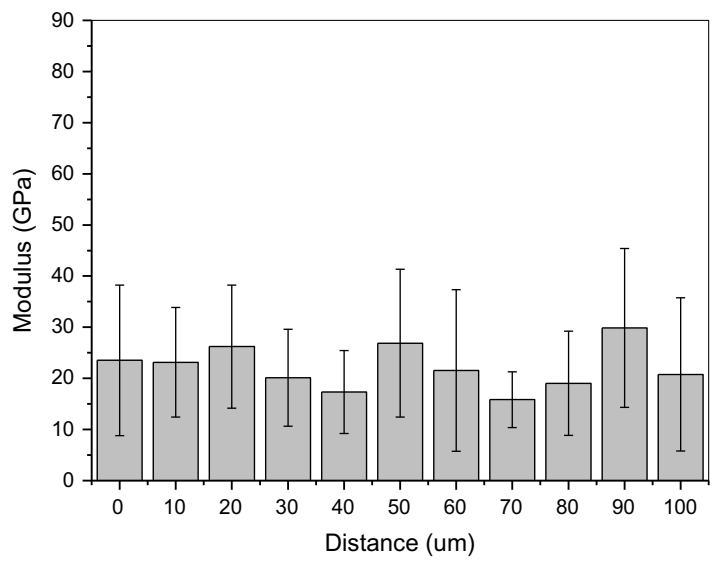

(c) Modulus distribution in new paste matrix

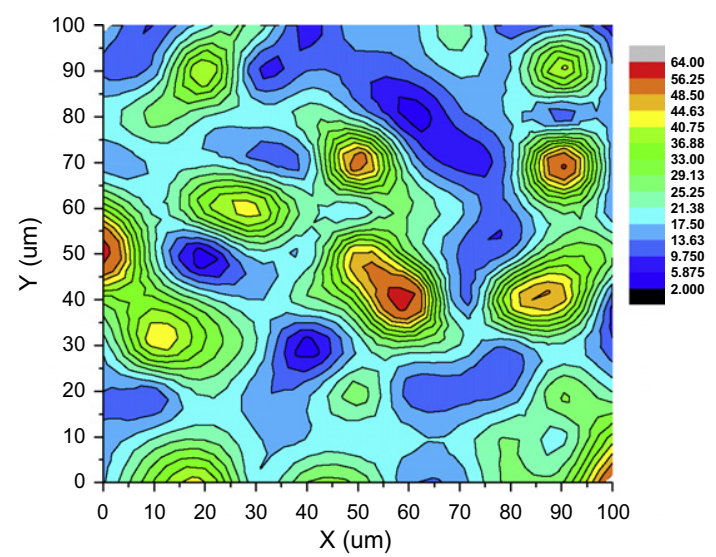

(b) Contour map of indentation modulus [GPa]

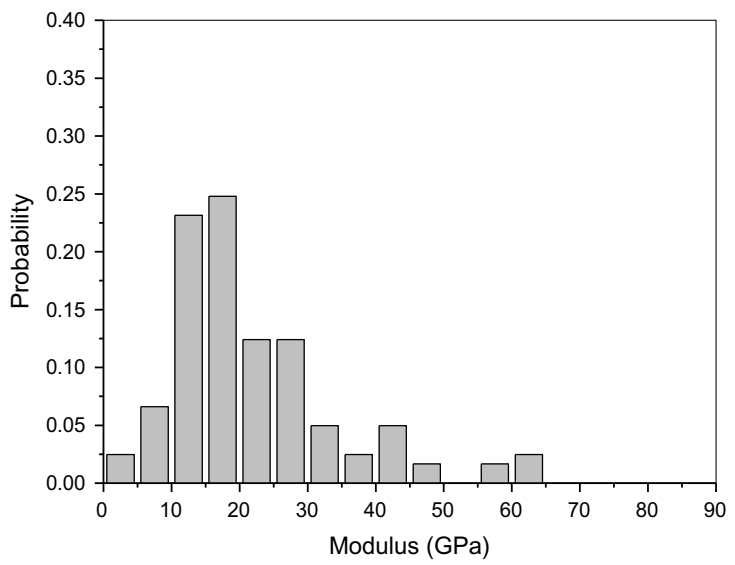

(d) Statistical analysis of modulus [bin size=5]

Fig. 14. Nanoindentation in new paste matrix.

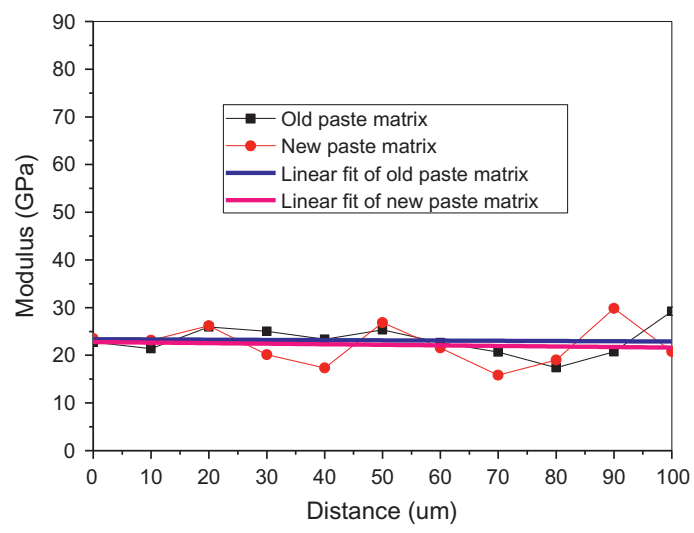

(a) General modulus distribution

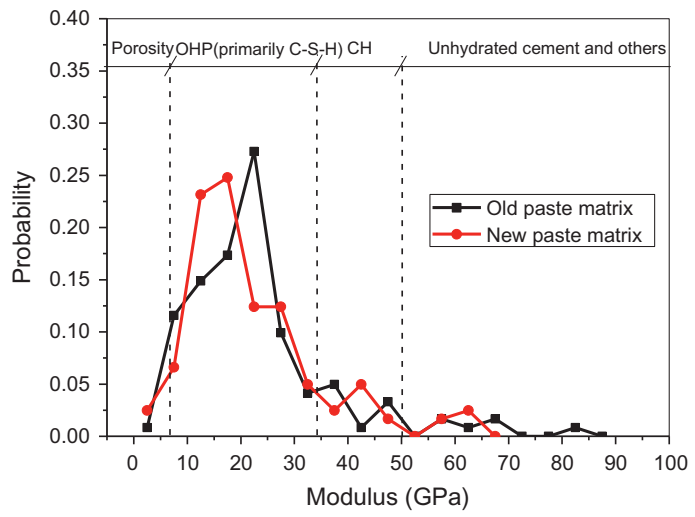

(b) General modulus statistic analysis

Fig. 15. Nanomechanical properties characteristics of old and new paste matrix in RAC.

in old ITZ and new ITZ with TSMA (Fig. 16c). The total volume of voids and $\mathrm{CH}$ crystals were significantly greater in the new ITZ with NMA. The variation in porosity, $\mathrm{CH}$, and ettringite crystals contents along with the different types of new ITZ can be assumed due to the different mixing approaches. The TSMA coated the RCA with cement paste providing a stronger new ITZ by filling up the voids and cracks of the old paste matrix adhered to RCA. Therefore, the enhanced ITZ property with the TSMA method can be a good reason for the improvement of the RAC compressive strength. It is also interesting to see that there is a stronger and denser zone in the vicinity of the new ITZ (Fig. 16d). The EDX analysis showed that the dense zone is most likely composed of calcium carbonate crystals which are probably due to the RCA surface carbonation (Fig. 17). 


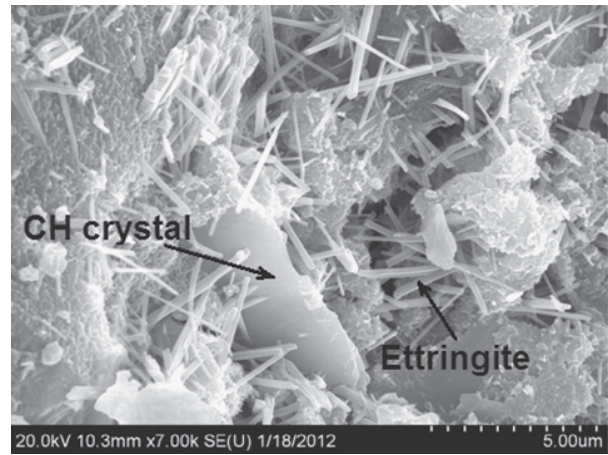

(a) Old ITZ around original aggregate (limestone)

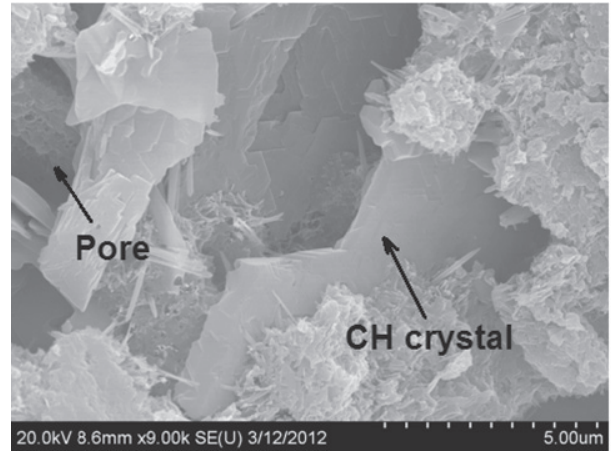

(c) New ITZ with NMA

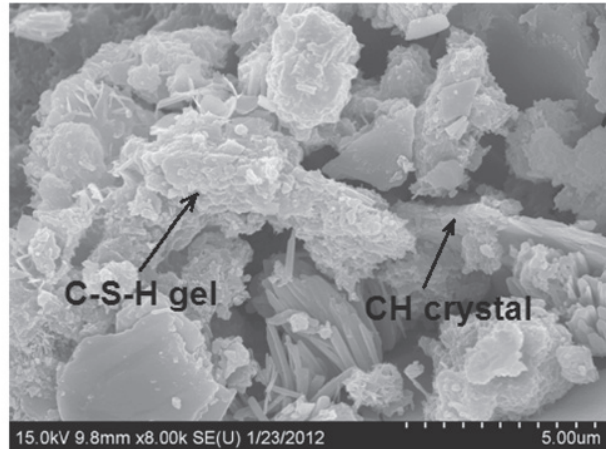

(b) New ITZ with TSMA

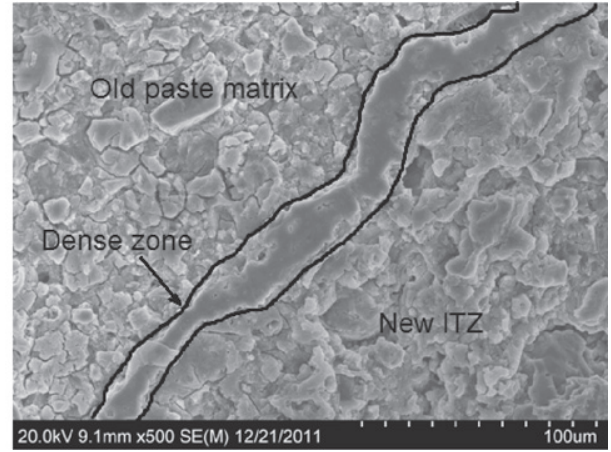

(d) Dense zone around new ITZ with TSMA

Fig. 16. Microstructure characteristics of ITZs in RAC.

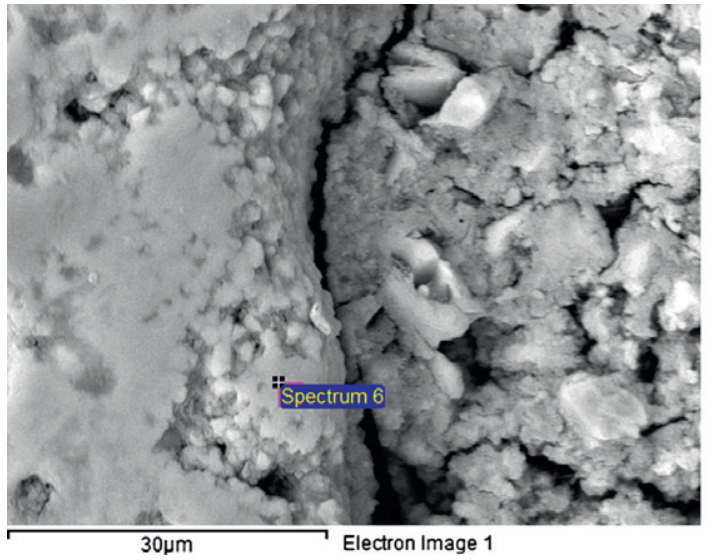

(a) EDX point on old paste matrix side

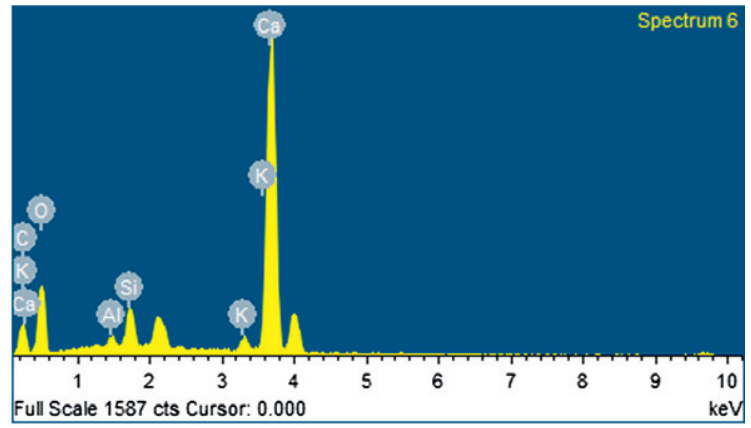

(b) EDX spectrum

Fig. 17. Energy dispersive X-ray analysis in new ITZ with NMA.

\section{Conclusions}

Detailed and quantitative analysis of SEM images and nanoindentation have drawn significant conclusions on microstructural characterization and the phase distributions of porosity, calcium hydroxide $(\mathrm{CH})$, the other hydration production (primarily $\mathrm{C}-\mathrm{S}-$ $\mathrm{H}$ ) and unhydrated cement for ITZs in RAC with different mixing approaches. The main conclusions are as follows:

(1) For the old ITZ, the indentation modulus increases as the distance from original aggregate surface increases. For the new ITZ with TSMA, there is no obvious trend indicating that the indentation modulus increases or decreases with the increasing distance from the old paste matrix surface, while in the new ITZ with NMA the modulus distribution appears to decrease significantly from the old paste matrix surface.

(2) It indicates that the TSMA can effectively reduce the size and effect of water layers and $\mathrm{CH}$ crystals formed around the RCA. Therefore, the amount of porosity is reduced and the enhanced hydration provides a source for production of $\mathrm{C}-\mathrm{S}-\mathrm{H}$.

(3) It is observed that the volume fractions of porosity and $\mathrm{CH}$ phases in the new ITZ with TSMA are relatively lower than those of the old ITZ and new ITZ with NMA, which can explain the improvement in RAC compressive strength. 
(4) For the new ITZ with TSMA, the cement slurry permeates into the porous old paste matrix and fills up the voids and cracks, which improve the microstructure of the new ITZ. However, for the new ITZ with NMA, there is a significantly loose microstructure that contains a large volume of porosity and $\mathrm{CH}$ crystals.

(5) It is interesting to note that there is a stronger and denser zone existing in the vicinity of the new ITZ in RAC. The EDX analysis exhibits that the dense zone with high indentation modulus is most likely the calcium carbonate crystals which covers the surface of RCA.

\section{Acknowledgments}

The authors would like to gratefully acknowledge the financial supports from the National Natural Science Foundation of China (51178340) and the Shanghai Science and Technology Committee (No. 10231202000) as well as the Kwang-Hua Foundation. The test was performed at the NIFTI facility of NUANCE Center in Northwestern University.

\section{References}

[1] RILEM Report 22. Sustainable raw materials: construction and demolition waste. In: Hendriks Ch F, Pietersen HS, editors. France: RILEM Publications S.A.R.L.; 2000.

[2] Xiao JZ, Li WG, Fan YH, Huang X. An overview of study on recycled aggregate concrete in China (1996-2011). Constr Build Mater 2012;31:364-83.

[3] Tam VWY, Gao XF, Tam CM. Microstructural analysis of recycled aggregate concrete produced from two-stage mixing approach. Cem Concr Res 2005;35(6):1195-203.

[4] Tam VWY, Gao XF, Tam CM. Comparing performance of modified two-stage mixing approach for producing recycled aggregate concrete. Mag Concr Res 2006;58(7):477-84.

[5] Tam VWY, Tam CM. Diversifying two-stage mixing approach (TSMA) for recycled aggregate concrete: TSMAs and TSMAsc. Constr Build Mater 2008;22(10):2067-77.

[6] Bordelon A, Cervantes V, Roesler JR. Fracture properties of concrete containing recycled concrete aggregates. Mag Concr Res 2009;61(9):665-70.

[7] Xiao JZ, Sun YD, Falkner H. Seismic performance of frame structures with recycled aggregate concrete. Eng Struc 2006;28(1):1-8.

[8] Shayan A, Xu A. Performance and properties of structural concrete made with recycled concrete aggregate. ACI Mater J 2003;100(5):371-80.

[9] Fathifazl G, Razaqpur AGO, Isgor OB, Abbas A, Fournier B, Foo S. Flexural performance of steel-reinforced recycled concrete beams. ACI Struc J 2009;106(6):858-67.

[10] Tam VWY, Tam CM. Assessment of durability of recycled aggregate concrete produced by two-stage mixing approach. J Mater Sci 2007;42(10):3592-602.

[11] Termpto A, Jeong HG, Lange DA, Maruyama I. Tensile properties of recycled aggregate concrete. Proc Jpn Concr Inst 2011;33(1):551-6.

[12] Erdem S, Dawson AR, Thom NH. Influence of the micro- and nanoscale local mechanical properties of the interfacial transition zone on impact behavior of concrete made with different aggregates. Cem Concr Res 2012;42(2):447-58.
[13] Akçaoğlu T, Tokyay M, Çelik T. Assessing the ITZ micro-cracking via scanning electron microscope and its effect o the failure behaviour of concrete. Cem Concr Res 2005;35(2):358-63.

[14] Liu Q Xiao JZ, Sun ZH. Experimental study on the failure mechanism of recycled concrete. Cem Concr Res 2011;41(10):1050-7.

[15] Otsuki N, Miyazato S, Yodsudjai W. Influence of recycled aggregate on interfacial transition zone, strength, chloride penetration and carbonation of concrete. J Mater Civ Eng 2003;15(5):443-51.

[16] Sorelli L, Constantinides G, Ulm F-J, Toutlemonde F. The nano-mechanical signature of ultra high performance concrete by statistical nanoindentation techniques. Cem Concr Res 2008;38(12):1447-56.

[17] Constantinides G, Ulm F-J. The effect of two types of C-S-H on the elasticity of cement-based materials: results from nanoindentation and micromechanical modeling. Cem Concr Res 2004;34(1):67-80.

[18] Mondal P, Shah SP, Marks LD. Nanoscale characterization of cementitious materials. ACI Mater J 2008;105(2):174-9.

[19] Wang XH, Jacobsen S, Lee SF, He JY, Zhang ZL. Effect of silica fume, steel fiber and ITZ on the strength and fracture behavior of mortar. Mater Struct 2010;43(1-2):125-39.

[20] Pope AW, Jennings HM. The influence of mixing on the microstructure of the cement paste/aggregate interfacial zone and the strength of mortar. J Mater Sci 1992;27(23):6452-62.

[21] Trtik P, Kaufmann J, Volz U. On the use of peak-force tapping atomic force microscopy for quantification of the local elastic modulus in hardened cement paste. Cem Concr Res 2012;42(1):215-21.

[22] Igarashi S, Bentur A, Mindess S. Microhardness testing of cementitious materials. Adv Cem Based Mater 1996;4(2):48-57.

[23] Xiao JZ, Li WG, Sun ZH, Lange DA, Shah SP. Studying interfacial transition zones in recycled aggregate concrete with nanoindentation. Submitted to Cem Concr Compos 2012, submitted for publication.

[24] Sakulich AR, Li VC. Nanoscale characterization of engineered cementitious composites (ECC). Cem Concr Res 2011;41(2):169-75.

[25] Oliver WC, Pharr GM. An improved technique for determining hardness and elasticmodulus using load and displacement sensing indentation experiments. J Mater Res 1992;7(6):1564-83.

[26] Ulm F-J, Vandamme M, Bobko C, Ortega JA, et al. Statistical indentation techniques for hydrated nanocomposites: concrete, bone, and shale. J Am Ceram Soc 2007;90(9):2677-92.

[27] Scrivener KL. Backscattered electron imaging of cementitious microstructures: understanding and quantification. Cem Concr Compos 2004;26(8):935-45.

[28] Diamond Sidney. The microstructure of cement paste and concrete-a visual primer. Cem Concr Compos 2004;26(8):919-33.

[29] Zhang MH, Chen JK, Zhu J, Chen JY. Experimental evaluation on modulus of equivalent homogeneous ettringite. Acta Mech Solida Sin 2009;22(4):320-7.

[30] Chamrova R. Modelling and measurement of elastic properties of hydrating cement paste. Ph.D thesis, Lab Constr Mater, Ecole Polytechnique Switzerland: Federale de Lausanne; 2010.

[31] Nemecek J, Smilauer V, Kopecky L. Nanoindentation characteristics of alkaliactivated aluminosilicate materials. Cem Concr Compos 2011;33(2):163-70.

[33] Allen1 Andrew J, Thomas2 Jeffrey J, Jennings Hamlin M. Composition and density of nanoscale calcium-silicate-hydrate in cement. Nature Mater 2007;6:311-6.

[33] Konsta-Gdoutos MS, Metaxa ZS, Shah SP. Multi-scale mechanical and fracture characteristics and early-age strain capacity of high performance carbon nanotube/cement nanocomposites. Cem Concr Compos 2010;32(2):110-5

[34] Constantinides G, Ulm FJ. The nanogranular nature of C-S-H. J Mech Phys Solids 2007;55(1):64-90.

[35] Breton D, Carles-Gibergues A, Ballivy G, Grandet J. Contribution to the formation mechanism of the transition zone between rock-cement paste. Cem Concr Res 1993;23(2):335-46.

[36] Bonen D. Calcium hydroxide deposition in the near interfacial zone in plain concrete. J Am Ceram Soc 1994;77(1):193-6. 